\title{
Early exposure to distinct sources of lipids affects differently the development and hepatic inflammatory profiles of $2 \mathrm{I}$-day-old rat offspring
}

This article was published in the following Dove Press journal: Journal of Inflammation Research

\section{Laís Vales Mennitti'}

Lila Missae Oyama ${ }^{2}$

Aline Boveto Santamarina'

Claudia Maria da Penha

Oller do Nascimento ${ }^{2}$

Luciana Pellegrini Pisani ${ }^{3}$

'PhD Program 'Interdisciplinar in Health Sciences', Federal University of São Paulo (UNIFESP), Santos, SP, Brazil; ${ }^{2}$ Department of Physiology, Discipline of Nutrition Physiology, Federal University of São Paulo (UNIFESP), São Paulo, SP, Brazil; ${ }^{3}$ Department of Biosciences, Institute of Health and Society, Federal University of São Paulo (UNIFESP), Santos, SP, Brazil
Correspondence: Luciana Pellegrini Pisani Federal University of São Paulo Rua Silva Jardim, I36, $3^{\circ}$ andar, Laboratório 311 , Vila Mathias, Santos, SP, Brazil

Tel +55 I39 8I 440230

Email lucianapisani@hotmail.com

\begin{abstract}
Introduction: Maternal diet composition of fatty acids during pregnancy and lactation seems to modify the fetal programming, epigenetic pattern and offspring phenotype.

Aim: Herein, we investigated the effects of maternal consumption of normal-fat diets with distinct lipid sources during pregnancy and lactation on the somatic development and proinflammatory status of 21-day-old rat offspring.

Materials and Methods: On the first day of pregnancy, female Wistar rats were divided into four groups as follows: soybean oil (M-SO), lard (M-L), hydrogenated vegetable fat (M-HVF) and fish oil (M-FO). Diets were maintained during pregnancy and lactation. Male offspring constituted the SO, L, HVF and FO groups. Pups were weighed and measured weekly. Lipopolysaccharide serum concentration was determined. Tumor necrosis factor alpha, interleukin (IL)-6 and IL-10 in the liver were evaluated by enzyme-linked immunosorbent assay. Liver gene expressions were determined by real-time polymerase chain reaction. Protein expressions in the liver were analyzed by Western blotting.

Results: We observed an increase in body weight and adiposity in L and HVF groups. Moreover, HVF group showed an increase in the toll-like receptor 4 mRNA levels, IL10R $\alpha$ and phosphorylated form of IKB kinase (IKK; $\mathrm{p}-\mathrm{IKK} \alpha+\beta$ ) protein expression. The FO group presented a decrease in body weight, relative weight of retroperitoneal adipose tissue, ADIPOR2 gene expression, lipopolysaccharide and $\mathrm{p}$-IKK $\alpha+\beta$ and phosphorylated form of nuclear transcription

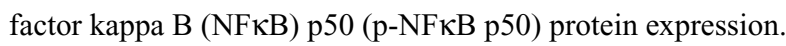

Conclusion: Summarily, whereas maternal intake of normal-fat diets based on L and HVF appear to affect the somatic development negatively, only early exposure to HVF impairs the pups' proinflammatory status. In contrast, maternal diets based on FO during pregnancy and lactation have been more beneficial to the adiposity and toll-like receptor 4 signaling pathway of the 21-day-old rat offspring, particularly when compared to L or HVF diets.
\end{abstract}

Keywords: fatty acids, pregnancy and lactation, adiposity, proinflammatory status, pups

\section{Introduction}

Several lines of evidence indicate a direct relationship of maternal nutrition during pregnancy and lactation with development from the fetal and newborn stages until adult life, likely influencing in the fetal programming and epigenetic patterning in the offspring. Phenotypic modifications triggered by inadequate maternal nutrition lead to increased risks of metabolic disorders such as obesity, type 2 diabetes, hypertension and cardiovascular disease (CVD). ${ }^{1-4}$

The maternal adipose stores and fatty acid (FA) composition in the diet during pregnancy and lactation are considered critical factors in adequate fetal growth and 
metabolism because they interfere directly with the profile of FAs that are transferred to the offspring through the placenta and breast milk. ${ }^{5,6}$ In fact, Elias and Innis ${ }^{7}$ showed that the concentrations of trans fatty acids (TFAs), linoleic acid (C18:2 n-6), arachidonic acid (C20:4 n-6), $\alpha$-linolenic acid (C18:3 n-3), docosahexaenoic acid (DHA; C22:6 n-3) and eicosapentaenoic acid (EPA; 20:5 n-3) in the maternal plasma phospholipids correlated with the concentrations of the same FAs in infant plasma immediately after delivery. Similarly, Priego et $\mathrm{al}^{8}$ detected higher percentages of palmitic acid (C16:0, representative of saturated fatty acids [SFAs]) in milk samples from dams exposed to a butter-supplemented diet from day 14 of pregnancy until day 20 of lactation.

Our research group and others investigated the influence of maternal exposure to different sources of lipids during pregnancy and/or lactation on the health status of the offspring during infancy and adulthood. Taken together, the results of these studies showed that the maternal intake of a diet enriched with SFAs and TFAs during the early life of the offspring has noxious effects on somatic and metabolic development, leading to the impairment of glucose and lipid homeostasis and/or an increase in inflammatory responses possibly mediated by toll-like receptor 4 (TLR4). ${ }^{9-19}$ In contrast, the maternal consumption of $n-3$ polyunsaturated fatty acids (PUFAs), especially EPA and DHA, during pregnancy and lactation seems to have beneficial effects on adiposity, insulin sensitivity, the proinflammatory status and epigenetic regulation in the pups, thereby decreasing the risks of developing obesity, insulin resistance and CVD. ${ }^{16,20-23}$

A modern diet based mainly on industrially processed foods is currently replacing traditional diets composed of mainly fresh, unprocessed and minimally processed foods. Ultra-processed products contain higher levels of added sugars, sodium and SFAs as well as lower amounts of dietary fiber. ${ }^{24}$ Together with the industrial production of TFAs from the conversion of liquid vegetable oils to solids with improved oxidative stability and shelf lives via partial hydrogenation, ${ }^{25}$ a substantial loss of n-3 PUFAs, which are structurally unstable, occurs during commercial processing. ${ }^{26}$ In a review, Das $^{26}$ reported that industrial progress has reduced the n-3 PUFA content in the human diet, which may be responsible for the increasing incidence of metabolic diseases.

Given this shift in dietary patterns and dietary lipid compositions in the population, we investigated the different effects of the maternal consumption of normal-fat diets with distinct lipid sources during pregnancy and lactation on the somatic development and proinflammatory status of 21-day-old rat offspring.

This manuscript hypothesizes that the quality of dietary FAs in the maternal diet may be as important as the quantity of these FAs in terms of the health status of the offspring; specifically, SFA and TFA can negatively modify the somatic development of the offspring and induce a proinflammatory state, whereas n-3 PUFA could ameliorate negative changes in corporal parameters and inflammatory responses in the offspring.

\section{Materials and methods Animals and diet}

The Ethic Research Committee/Animal Use Ethic Commission (CEUA) of the Federal University of São Paulo approved all procedures for the care of the animals used in this study (CEUA protocol $n^{\circ} 1427180914$ ) and followed the internationally recognized guidelines "Principles of Laboratory Animal Care" formulated by the National Institutes of Health. Female and male Wistar rats of age 1 month were obtained from Centro Multidisciplinar para Investigação Biológica na Área da Ciência em Animais de Laboratório - Universidade Estadual de Campinas. The rats were kept under controlled conditions of light ( $12 \mathrm{~h}$ light $/ 12 \mathrm{~h}$ dark cycle with lights on at 07:00 am) and temperature $\left(24^{\circ} \mathrm{C} \pm 1^{\circ} \mathrm{C}\right)$ with ad libitum water and food all the time. When the animals completed 3 months of age, female rats weighing $\sim 250 \mathrm{~g}$ were left overnight to mate, and copulation was verified the following morning by the presence of sperm in vaginal smears.

On the first day of pregnancy, the dams were isolated in individual polyethylene cages and sequentially divided into four groups, each receiving one of four diets: a soybean oil diet (M-SO group), a lard diet (M-L group), a hydrogenated vegetable fat diet (M-HVF group) or a fish oil diet (M-FO group). The experimental diets were maintained throughout the period of pregnancy and lactation. At birth, the pups remained in the same group as the mother, composing the following experimental groups: SO, L, HVF and FO. Four diets were prepared according to the recommendations of the American Institute of Nutrition (AIN-93G), ${ }^{27,28}$ in which a similar calorific and lipid content was maintained and they differed from each other only in the source of lipid offered. The source of lipids for the SO diet was soybean oil (rich in n-6 PUFA), L diet was lard (rich in SFAs), HVF diet was partially hydrogenated vegetable fat (rich in TFAs) and FO diet was fish oil (rich in n-3 PUFA). Table 1 shows the lipid nutritional information provided by the manufacturers of the fats used to prepare the experimental diets. Soybean oil ( $1 \mathrm{~g} / 100 \mathrm{~g}$ of diet) was added to L, HVF and FO diets to meet the minimum requirement for essential FAs. The centesimal composition of the experimental diets is presented in Table 2.

On the day of delivery (day 0 of lactation), the litter sizes were standardized to eight pups each with an effort to 
Table I Lipid nutritional information of different fats according to manufacturers of the industrial products used to prepare the experimental diets

\begin{tabular}{|c|c|c|c|c|c|}
\hline \multicolumn{6}{|c|}{ Lipid nutritional information of different fats ${ }^{a}$} \\
\hline Experimental fats & $\begin{array}{l}\text { Saturated fatty } \\
\text { acids }(\mathrm{g} / 100 \mathrm{~g})\end{array}$ & $\begin{array}{l}\text { Trans fatty } \\
\text { acids (g/100 g) }\end{array}$ & $\begin{array}{l}\text { Polyunsaturated } \\
\text { fatty acids (g/1 } 00 \mathrm{~g})\end{array}$ & EPA (g/l $00 \mathrm{~g})$ & DHA (g/lo0 g) \\
\hline Soy oil (Liza) ${ }^{b}$ & 16.9 & 0.0 & 59.9 & ND & ND \\
\hline Lard (Sadia) ${ }^{c}$ & 39.0 & 0.0 & ND & ND & ND \\
\hline Hydrogenated vegetable fat $\left(\text { Saúde }^{\circledR}\right)^{d}$ & 25.0 & 37.0 & ND & ND & ND \\
\hline Fish oil (MEG-3" “75" n-3 EE oil) ${ }^{\mathrm{e}}$ & ND & ND & 74.8 & 42.2 & 22.7 \\
\hline
\end{tabular}

Notes: anformation presented in this table was obtained on the food label provided by the original manufacturers. bSoy oil was obtained from a local supermarket (Cargill - Brazilian industry). Ingredients: 100\% genetically modified refined soy oil (Agrobacterium tumefaciens and Bacillus thuringiensis). 'Lard was obtained from a local supermarket

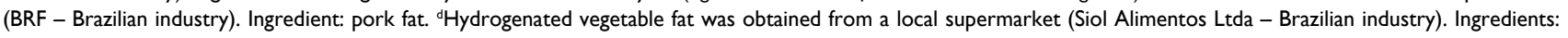

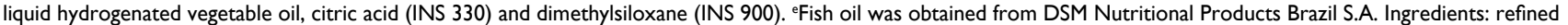
n-3 polyunsaturated fatty acid ethyl esters, mixed tocopherols, rosemary extract and ascorbyl palmitate.

Abbreviations: EPA, eicosapentaenoic acid; DHA, docosahexaenoic acid; ND, not declared.

Table 2 Centesimal composition of the SO, L, HVF and FO diet (AIN-93G)

\begin{tabular}{|c|c|c|c|c|}
\hline \multirow[t]{2}{*}{ Ingredient } & \multicolumn{4}{|c|}{ Diet (g/l00 g) } \\
\hline & so & $\mathbf{L}$ & HVF & FO \\
\hline Casein $^{\mathrm{a}}$ & 20.0 & 20.0 & 20.0 & 20.0 \\
\hline l-cystine ${ }^{b}$ & 0.3 & 0.3 & 0.3 & 0.3 \\
\hline Corn starch ${ }^{c}$ & 52.949 & 52.949 & 52.949 & 52.949 \\
\hline Sucrose $^{d}$ & 10.0 & 10.0 & 10.0 & 10.0 \\
\hline $\mathrm{SO}^{\mathrm{e}}$ & 8.0 & 1.0 & 1.0 & 1.0 \\
\hline$L^{f}$ & - & 7.0 & - & - \\
\hline HVFg & - & - & 7.0 & - \\
\hline $\mathrm{FO}^{\mathrm{h}}$ & - & - & - & 7.0 \\
\hline Butylhydroquinone $^{b}$ & 0.0014 & 0.0014 & 0.0014 & 0.0014 \\
\hline Mineral mixture & 3.5 & 3.5 & 3.5 & 3.5 \\
\hline Vitamin mixture & 1.0 & 1.0 & 1.0 & 1.0 \\
\hline Cellulose $^{b}$ & 5.0 & 5.0 & 5.0 & 5.0 \\
\hline Choline bitartrate $^{\mathrm{b}}$ & 0.25 & 0.25 & 0.25 & 0.25 \\
\hline Energy (kcal/g) & 4.1 & 4.1 & 4.1 & 4.1 \\
\hline
\end{tabular}

Notes: ${ }^{a}$ Casein was obtained from Labsynth, São Paulo, Brazil. 'l-cystine, butylhydroquinone, cellulose and choline bitartrate were commercialized by Rhoster, Brazil. ' Corn starch was obtained from Amilogill ${ }^{\circledR} 2100$ (Cargill - Ind. Brazil). 'Sucrose was obtained from União (from a local supermarket; Brazilian industry). " $S O$ was obtained from Liza (from a local supermarket; Cargill - Brazilian industry). ' $L$ was obtained from Sadia (from a local supermarket; BRF - Brazilian industry). gHVF was supplied by Saúde (from a local supermarket; Siol Alimentos Ltda - Brazilian industry) "FO was obtained from DSM Nutritional Products Brazil S.A. MEG-3" “75" n-3 EE oil. inineral mixture: calcium, $5000 \mathrm{mg} / \mathrm{kg}$; phosphorus, $156 \mathrm{I} \mathrm{mg/kg;} \mathrm{potassium,} 3600 \mathrm{mg}$ $\mathrm{kg}$; sodium, 1019 mg/kg; chloride, I $157 \mathrm{I} \mathrm{mg/kg;} \mathrm{sulfur,} 300 \mathrm{mg} / \mathrm{kg}$; magnesium, $507 \mathrm{mg} / \mathrm{kg}$; iron, $35 \mathrm{mg} / \mathrm{kg}$; copper, $6.0 \mathrm{mg} / \mathrm{kg}$; manganese, $10.0 \mathrm{mg} / \mathrm{kg}$; zinc, $30.0 \mathrm{mg} / \mathrm{kg}$; chromium, $1.0 \mathrm{mg} / \mathrm{kg}$; iodine $0.2 \mathrm{mg} / \mathrm{kg}$; selenium, $0.15 \mathrm{mg} / \mathrm{kg}$; fluoride, $1.00 \mathrm{mg} / \mathrm{kg}$; boron, $0.50 \mathrm{mg}$ $\mathrm{kg}$; molybdenum, $0.15 \mathrm{mg} / \mathrm{kg}$; silicon, $5.0 \mathrm{mg} / \mathrm{kg}$; nickel mg/kg, 0.5; lithium, $0.1 \mathrm{mg} / \mathrm{kg}$; vanadium, $0.1 \mathrm{mg} / \mathrm{kg}$ (AIN-93G, mineral mix, Rhoster, Brazil). Vitamin mixture: thiamin $\mathrm{HCl}, 6.0 \mathrm{mg} / \mathrm{kg}$; riboflavin, $6.0 \mathrm{mg} / \mathrm{kg}$; pyridoxine $\mathrm{HCl}, 7.0 \mathrm{mg} / \mathrm{kg}$; niacin, $30.0 \mathrm{mg} / \mathrm{kg}$; calcium pantothenate, $16.0 \mathrm{mg} / \mathrm{kg}$; folic acid, $2.0 \mathrm{mg} / \mathrm{kg}$; biotin, $0.2 \mathrm{mg} / \mathrm{kg}$; vitamin $\mathrm{BI}$, $25.0 \mathrm{mg} / \mathrm{kg}$; vitamin A palmitate, $4000 \mathrm{IU}$; vitamin E acetate, $75 \mathrm{mg} / \mathrm{kg}$; vitamin D3, 1000 IU; vitamin KI, 0.75 mg/kg (AIN-93G, vitamin mix, Rhoster, Brazil).

Abbreviations: FO, fish oil; HVF, hydrogenated vegetable fat; $L$, lard; SO, soybean oil.

maintain the largest possible number of males. Parturition was not induced and newborn rat offspring not added to this research were euthanized by decapitation after delivery. Pups were weighed and measured (naso-anal length) weekly as follows: at birth and 7th, 14th and 21 st days postnatally.

\section{Experimental procedures}

Male pups were used for the body composition and molecular analyses. On postnatal day 21 , the offspring were euthanized by decapitation in the specific laboratory room from 08:00 to 10:00 am. Dams were fasted for $10 \mathrm{~h}$; however, the 21-dayold offspring were not fasted to avoid weaning stress and all possible efforts were made to minimize suffering of animals. Trunk blood was collected and then immediately centrifuged at $2500 \mathrm{rpm}$ for 15 minutes. The serum was then separated and stored at $-80^{\circ} \mathrm{C}$ for determination of lipopolysaccharides (LPS) later. Retroperitoneal white adipose tissue (RET) was removed and weighed. Liver was isolated, immediately frozen in liquid nitrogen and stored at $-80^{\circ} \mathrm{C}$ for the subsequent performance of real-time polymerase chain reaction (RT-PCR), Western blotting analysis and enzyme-linked immunosorbent assay (ELISA).

\section{Serum determination of LPS}

Concentration of LPS in serum was assessed using the Limulus Amebocyte Lysate assay, a quantitative test for detecting endotoxin (QCL-1000 assay; Lonza, Walkersville, MD, USA). First, all materials were autoclaved to render them pyrogen free, avoiding any interference in the test. Serum samples were diluted 10 times with pyrogen-free water and incubated into pyrogen-free tubes at $75^{\circ} \mathrm{C}$ for 10 minutes. Standard curve used in the assay was generated by known concentrations of LPS of the strain Escherichia coli O111:B4.

\section{Protein content of interleukin (IL)-6, IL-I 0 and tumor necrosis factor alpha (TNF- $\alpha$ ) in the liver determined by ELISA}

After euthanasia of the 21-day-old pups, $\sim 0.1 \mathrm{~g}$ of liver was removed and homogenized in $800 \mu \mathrm{L}$ of chilled extraction 
buffer (100 mM Trizma base pH 7.5, 20 mM EDTA, $100 \mathrm{mM}$ sodium fluoride, $100 \mathrm{mM}$ sodium pyrophosphate, $10 \mathrm{mM}$ sodium orthovanadate, $2 \mathrm{mM}$ phenylmethylsulfonyl fluoride and $0.1 \mathrm{mg} / \mathrm{mL}$ of aprotinin) prepared on the day of experiment. After homogenization using a polytron, $80 \mu \mathrm{L}$ of $10 \%$ Triton X-100 was added to each sample. After 30 minutes, the homogenate was centrifuged (14,000 rpm, 40 minutes, $\left.4^{\circ} \mathrm{C}\right)$. The supernatant was saved and total protein concentrations were determined using Bradford assay (Bio-Rad Laboratories Inc., Hercules, CA, USA) with bovine serum albumin as a reference. During all steps, the samples remained on ice in order to prevent protein degradation.

Quantitative assessment of TNF- $\alpha$, IL-6 and IL-10 protein content was carried out using ELISA kits (DuoSet ELISA; R\&D Systems, Minneapolis, MN, USA) following the recommendations of the manufacturer.

\section{RNA extraction and RT-PCR}

Total RNA from the liver was extracted with TRIzol ${ }^{\circledR}$ Reagent (Thermo Fisher Scientific, Waltham, MA, USA) according to the manufacturer's recommendations. The total RNA concentration per microliter was measured using a spectrophotometer, NanoDrop ND-1000 (NanoDrop Technologies Inc., Wilmington, DE, USA), and the readings were acquired at wavelengths of 260 and $280 \mathrm{~nm}$. The purity was estimated by the $260 / 280 \mathrm{~nm}$ ratio, which must range between 1.8 and 2.0 for nucleic acids. All samples were maintained at $-80^{\circ} \mathrm{C}$ for posterior analysis.

TLR4, ADIPOR2, TNFRI and IL6R mRNA levels from the liver were quantified by RT-PCR. Two micrograms of each total RNA sample were reverse transcribed using an M-MLV Reverse Transcriptase kit (Promega Corporation, Madison, WI, USA), and complementary DNA was synthesized to a final volume of $20 \mu \mathrm{L}$. Relative levels of TLR4, ADIPOR2, TNFR1 and IL6R mRNA were quantified in RT-PCR using an
SYBR Green primer in a ABI Prism 7500 Sequence Detector (both from Thermo Fisher Scientific). Relative levels of the housekeeping gene HPRT were measured for the analysis of results. The primers used are shown in Table 3. Results were obtained using the Sequence Detector software (Thermo Fisher Scientific) and were expressed as the relative increase using the method of $2^{-\Delta \Delta \mathrm{Ct}}$ previously described by Livak and Schmittgen. $^{29}$

\section{Protein analysis by Western blotting in the liver of $2 \mathrm{I}$-day-old rat offspring}

For these analyses, the same liver supernatant extracted to perform the ELISA method was used. The homogenized samples were treated with Laemmli buffer $(0.01 \%$ bromophenol blue, $100 \mathrm{mM}$ sodium phosphate $\mathrm{pH} 7.0,50 \%$ glycerol, $10 \%$ sodium dodecyl sulfate) at a ratio of $4: 1$ containing $100 \mathrm{mM}$ dithiothreitol. Proteins $(50 \mu \mathrm{g})$ were boiled for 5 minutes before loading onto $10 \%$ sodium dodecyl sulfatepolyacrylamide gel electrophoresis in a Bio-Rad miniature slab gel apparatus (Bio-Rad Laboratories Inc.). Electrotransfer of proteins from the gel to the nitrocellulose membrane was performed for $\sim 90$ minutes/four gels at $15 \mathrm{~V}$ (constant) in a Bio-Rad semi-dry transfer apparatus (Bio-Rad Laboratories Inc.). Nonspecific protein binding to the nitrocellulose membrane was reduced by overnight preincubation at $22^{\circ} \mathrm{C}$ in blocking buffer composed of basal solution (100 mM Trizma base $\mathrm{pH} 7.5,500 \mathrm{mM} \mathrm{NaCl}, 0.02 \%$ of Tween 20 ) containing $1 \%$ bovine serum albumin.

The nitrocellulose membranes were incubated overnight at $22^{\circ} \mathrm{C}$ with antibodies against the proteins presented in Table 4. Antibodies were diluted (Table 4) with blocking buffer and then washed for 30 minutes in basal solution. The blots were subsequently incubated with a peroxidaseconjugated secondary antibody for $1 \mathrm{~h}$ at $22^{\circ} \mathrm{C}$. To evaluate protein loading, membranes were stripped and reblotted with

Table 3 Primer sequences used in the performance of RT-PCR in the liver of 21 -day-old pups

\begin{tabular}{ll}
\hline Target genes & Sequences \\
\hline TLR4 & 5'-GCA TCA TCT TCA TTG TCC TTG AGA-3' (forward) \\
ADIPOR2 & 5'-CTA CCT TTT CGG AAC TTA GGT CTA CT-3' (reverse) \\
TNFRI & 5'-ATG TTT GCC ACC CCT CAG TA-3' (forward) \\
& 5'-CAG ATG TCA CAT TTG GCA GG-3' (reverse) \\
IL6R & 5'-GAA CAC CGT GTG TAA CTG CC-3' (forward) \\
& 5'-ATT CCT TCA CCC TCC ACC TC-3' (reverse) \\
HPRT & 5'-AAG CAG GTC CAG CCA CAA TGT AG-3' (forward) \\
& 5'-CCA ACT GAC TTT GAG CCA ACG AG-3' (reverse) \\
& 5'-CTC ATG GAC TGA TTA TGG ACA GGA C-3' (forward) \\
& 5'-GCA GGT CAG CAA AGA ACT TAT AGC C-3' (reverse) \\
\hline
\end{tabular}

Abbreviation: RT-PCR, real-time polymerase chain reaction. 
Table 4 Specifications of antibodies used in the Western blotting analysis

\begin{tabular}{|c|c|c|c|}
\hline Antibody & Company & Code & Dilution \\
\hline TNFRI (polyclonal) & Abcam, Cambridge, UK & abl9139 & $\mathrm{I}: 10,000$ \\
\hline IL6R $\alpha$ (polyclonal) & Santa Cruz Biotechnology, Santa Cruz, CA, USA & sc- 660 & $\mathrm{I}: 1000$ \\
\hline ILIOR $\alpha$ (polyclonal) & Santa Cruz Biotechnology, Santa Cruz, CA, USA & sc-984 & $\mathrm{I}: 1000$ \\
\hline ADIPOR2 (polyclonal) & Abcam, Cambridge, UK & $a b 77612$ & $\mathrm{I}: 5000$ \\
\hline TLR4 (monoclonal) & Abcam, Cambridge, UK & ab30667 & $\mathrm{I}: 5000$ \\
\hline MyD88 (polyclonal) & Abcam, Cambridge, UK & ab2064 & $1: 10,000$ \\
\hline TRAF6 (monoclonal) & Abcam, Cambridge, UK & ab33915 & $\mathrm{I}: 5000$ \\
\hline $\mathrm{p}-\mathrm{IKK} \alpha+\beta$ (polyclonal) & Abcam, Cambridge, UK & abl95907 & $\mathrm{I}: 5000$ \\
\hline p-NFKB p50 (polyclonal) & Santa Cruz Biotechnology, Santa Cruz, CA, USA & sc- 101744 & $\mathrm{I}: 1000$ \\
\hline p-NFKB p65 (polyclonal) & Abcam, Cambridge, UK & abl94726 & $\mathrm{I}: 5000$ \\
\hline$\beta$-actin (polyclonal) & Abcam, Cambridge, UK & $a b 75186$ & $\mathrm{I}: 10,000$ \\
\hline Rabbit (secondary antibody) & Santa Cruz Biotechnology, Santa Cruz, CA, USA & sc-2004 & $\mathrm{I}: 5000$ \\
\hline Rabbit (secondary antibody) & Abcam, Cambridge, UK & ab9705I & $\mathrm{I}: 5000$ \\
\hline Goat (secondary antibody) & Abcam, Cambridge, UK & ab97100 & $\mathrm{I}: 10,000$ \\
\hline Mouse (secondary antibody) & Abcam, Cambridge, UK & ab97023 & $\mathrm{I}: 5000$ \\
\hline
\end{tabular}

Abbreviations: ADIPOR2, adiponectin receptor 2; IL6R $\alpha$, interleukin 6 receptor alpha; ILIOR $\alpha$, interleukin 10 receptor alpha; MyD88, myeloid differentiation factor 88; $p$-IKK $\alpha+\beta$, phosphorylated form of IKB kinase $\alpha+\beta$; $p-N F \kappa B p 50$, phosphorylated form of nuclear transcription factor kappa $B$ p50 subunit; $p-N F \kappa B$ p 65 , phosphorylated form of nuclear transcription factor kappa B p65 subunit; TLR4, toll-like receptor 4; TNFRI, tumor necrosis factor receptor I; TRAF6, TNF receptor-associated factor 6.

an anti- $\beta$-actin antibody as appropriate. Specific bands were detected by chemiluminescence following addition of ECL reagent (Amersham/GE), and the capture was performed by exposure to Alliance 4.7 equipment (Uvitec, Cambridge, UK). Band intensities were determined by optical densitometry (Scion Image-Release Beta 3b; NIH, Frederick, $\mathrm{MD}, \mathrm{USA})$.

\section{Statistics analyses}

First of all, Grubbs' test (GraphPad Software, Inc., La Jolla, CA, USA) was performed to remove significant outlier samples. ${ }^{30}$ The statistical significance of the differences among the means of the four groups was assessed using a one-way analysis of variance (relative weight of RET, LPS serum concentration, gene expression and protein levels in liver) or analysis of variance for repeated measure (corporal parameters of dams and offspring), followed by a Bonferroni post hoc test.

All statistical tests were performed using the IBM SPSS Statistics 22 program. The other functions were executed using the Microsoft Excel 2010 program. All results are presented as the means \pm standard error of the mean, and differences were considered to be significant when $p \leq 0.05$.

\section{Results}

\section{Maternal body weight, body weight gain, metabolic efficiency and food intake}

To adequately interpret the data from pups presented in our study, we also evaluated the maternal corporal parameters, food intake and metabolic efficiency (ratio of food intake to body weight gain) of dams during pregnancy and/or lactation. Accordingly, body weights and food intake were measured weekly throughout the experimental period. No significant differences were observed in the maternal body weight or body weight gain during pregnancy and lactation (Figure 1). However, we observed an increase in food intake only during the first week of pregnancy in the mothers of the HVF group (M-HVF group) relative to the M-L ( $p=0.036)$ and M-FO ( $p=0.014$ ) groups (Figure 1B), although changes in metabolic efficiency were not observed during the same treatment period (Figure 1D).

\section{Corporal parameters and RET relative weights of $2 \mathrm{I}$-day-old rat offspring}

The body weight at birth and body weight gain during the second week of treatment were significantly lower in the FO group than in the SO $(p<0.001$ and $p<0.001$, respectively), $\mathrm{L}(p<0.001$ and $p<0.001$, respectively) and HVF groups $(p<0.001$ and $p<0.001$, respectively), as shown in Figure $2 \mathrm{~A}$ and $\mathrm{C}$, respectively. Moreover, the HVF group exhibited a significantly reduced body weight at birth, compared to the SO ( $p=0.032)$ and L ( $p=0.048)$ groups (Figure $2 \mathrm{~A})$. By postnatal day 7 , the body weight of the $\mathrm{FO}$ group remained lower than that of the SO group ( $p=0.006$; Figure $2 \mathrm{~A}$ ). Similarly, on days 14 and 21, we observed lower body weights in the FO group than in the $\mathrm{SO}(p<0.001$ and $p=0.038$, respectively), $\mathrm{L}(p<0.001$ and $p<0.001$, respectively) and HVF $(p<0.002$ and $p<0.001$, respectively) groups (Figure $2 \mathrm{~A}$ ). However, the $\mathrm{L}(p=0.016$ and $p<0.001$, respectively) and HVF $(p<0.001$ and $p<0.001$, respectively) groups exhibited significantly 
A
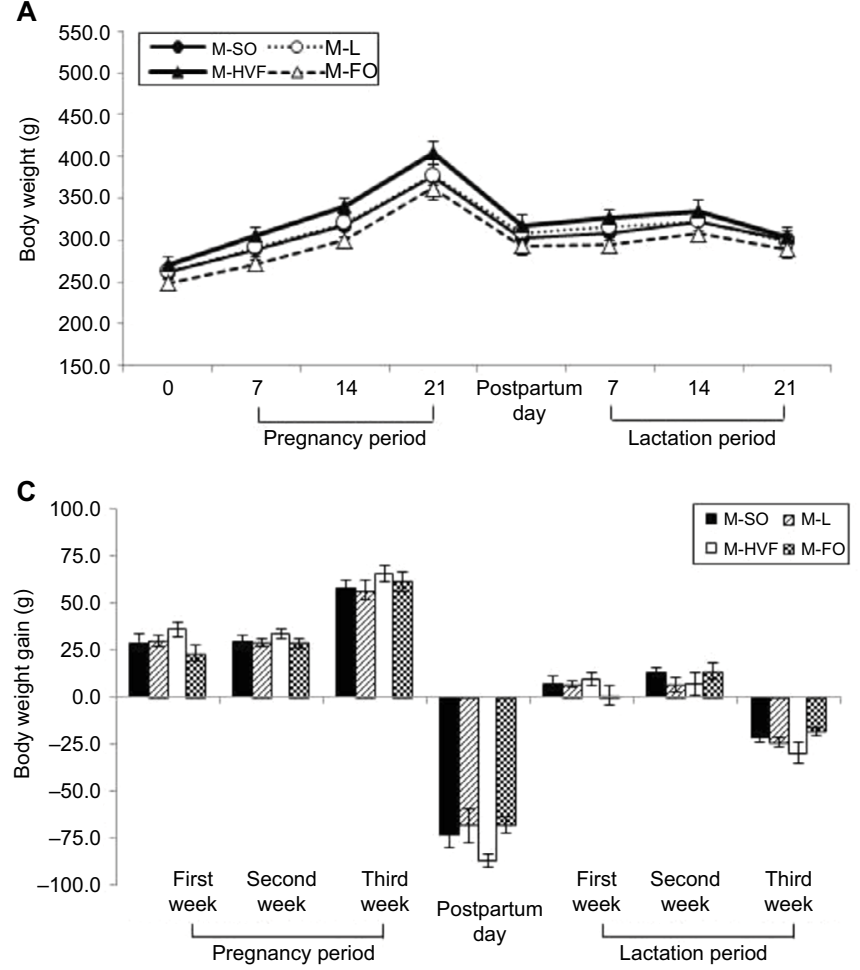

B

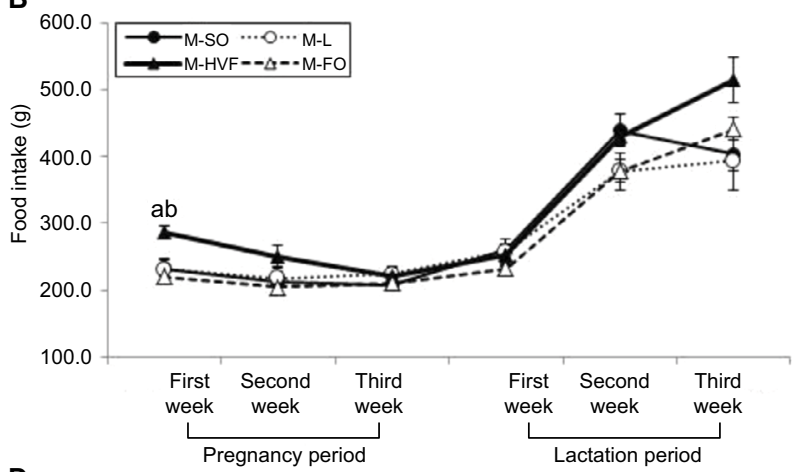

D
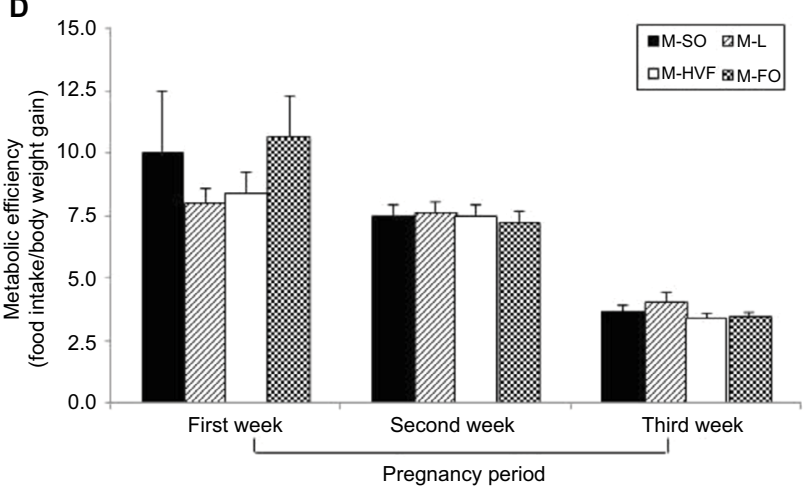

Figure I Effects of dietary consumption of distinct sources of lipids on corporal parameters, food intake and metabolic efficiency of dams during pregnancy and lactation periods.

Notes: (A) Maternal body weight. (B) Maternal food intake. (C) Maternal body weight gain. (D) Maternal metabolic efficiency. M-SO - mothers that were fed control diet; $M-L$ - mothers that were fed diet enriched with lard; M-HVF - mothers that were fed diet enriched with hydrogenated vegetable fat; M-FO - mothers that were fed diet enriched with FO. Groups were compared by ANOVA for repeated measure, followed by a Bonferroni post hoc test. Data are mean \pm SEM of five to six determinations per group. ${ }^{a} p \leq 0.05$ versus $M-L .{ }^{b} p \leq 0.05$ versus $M-F O$.

Abbreviations: ANOVA, analysis of variance; FO, fish oil; HVF, hydrogenated vegetable fat; L, lard; SEM, standard error of the mean; SO, soybean oil.

higher body weights and body weight gains relative to the $\mathrm{SO}$ group at the end of the experimental period (Figure 2A and $\mathrm{C}$, respectively). Additionally, the body weight gains in the HVF group were greater than those in the $\mathrm{L}$ group $(p=0.007$; Figure 2C). Finally, in the third week of treatment, animals in the FO group had gained less weight than those in the $\mathrm{L}$ $(p=0.002)$ and HVF $(p<0.001)$ groups (Figure $2 \mathrm{C})$.

We also found that pups in the FO group had shorter body lengths relative to those in the SO $(p<0.001, p<0.001$ and $p<0.001$, respectively), $\mathrm{L}(p<0.001, p<0.001$ and $p<0.001$, respectively) and HVF ( $p<0.001, p=0.003$ and $p=0.010$, respectively) groups from birth to postnatal day 14 (Figure 2B). By postnatal days 7 and 14, animals in the HVF group were shorter in length than those in the SO group ( $p=0.026$ and $p=0.013$, respectively). Finally, on postnatal day 21 , pups in the FO group were similar in length to those in the SO group and significantly shorter than those in the $\mathrm{L}(p=0.004)$ and HVF $(p<0.001)$ groups. Furthermore, pups in the HVF group were longer than those in the $\mathrm{SO}$ group ( $p=0.031$; Figure $2 \mathrm{~B}$ ).

The weight of the retroperitoneal adipose tissue, a visceral fat deposit, was evaluated in the rat offspring as a measure of the partial visceral adiposity. The relative weight of RET was lower in the FO group than in the $\mathrm{SO}(p<0.001), \mathrm{L}(p<0.001)$ and HVF $(p<0.001)$ groups. However, the L and HVF groups exhibited increased tissue weights relative to the SO group ( $p=0.002$ and $p=0.003$, respectively; Figure 2D).

\section{Serum concentration of LPS, hepatic protein contents of TNF- $\alpha$, IL- 6 and IL- 10 and the hepatic IL-I0/TNF- $\alpha$ ratio in 21 -day-old rat offspring}

The serum LPS concentration was significantly decreased in the FO group, compared with the L group ( $p=0.019$; Table 5). The protein liver contents of TNF- $\alpha$, IL- 6 and IL-10 were similar among the SO, L, HVF and FO groups (Table 5).

\section{TLR4, IL6R, TNFRI and ADIPOR2 gene expression in the livers of 21 -day-old rat offspring}

The relative TLR4 mRNA levels in the liver were higher in the HVF group than in the SO $(p=0.021), \mathrm{L}(p=0.008)$ and 

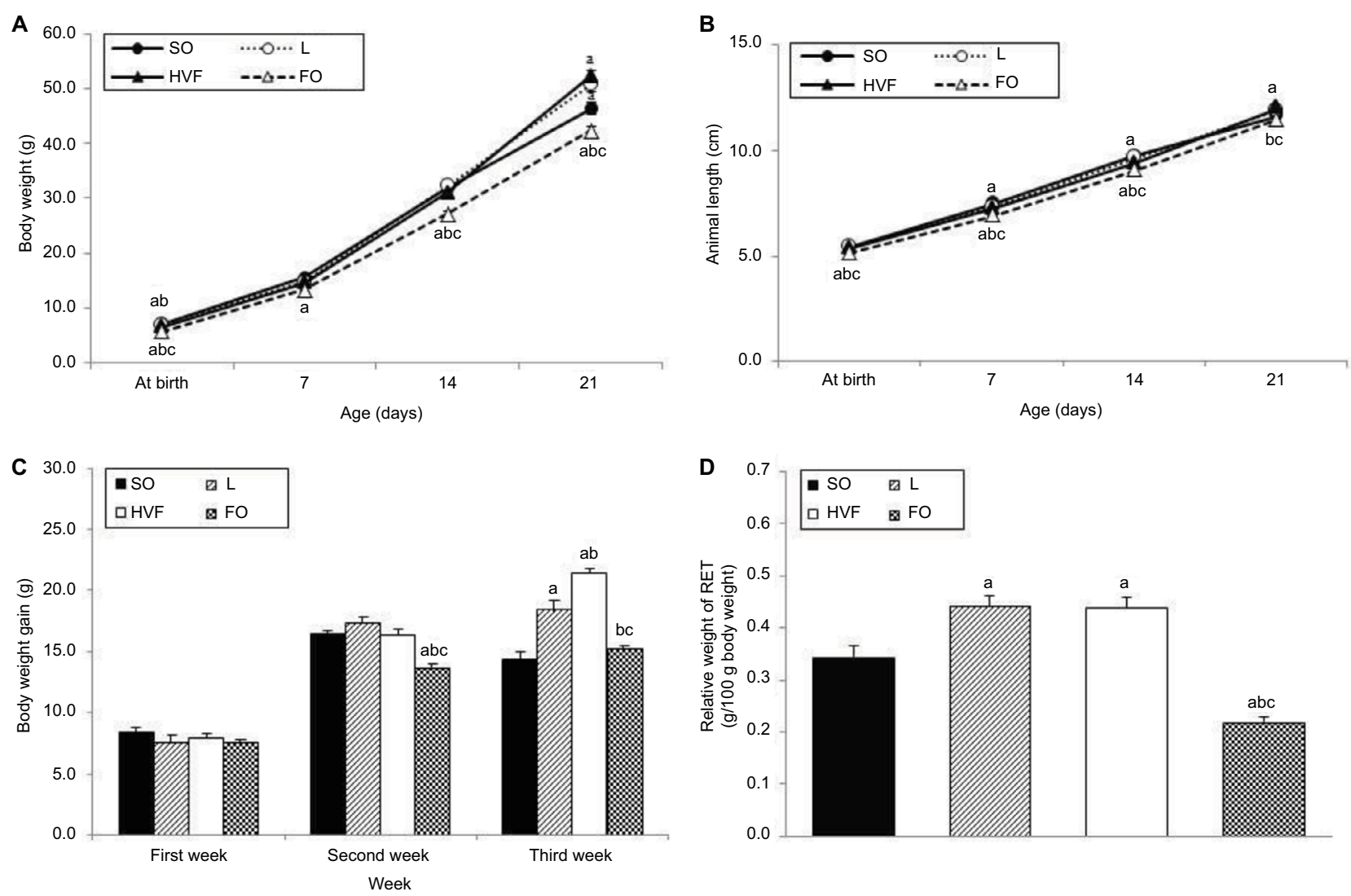

Figure 2 Effects of maternal intake of distinct sources of lipids during pregnancy and lactation on corporal parameters of the 2I-day-old rat offspring.

Notes: (A) Body weight (g). (B) Animal length (cm). (C) Body weight gain (g). (D) Relative weight of RET ( $\mathrm{g} / 100 \mathrm{~g}$ of body weight). SO - 2l-day-old offspring of mothers fed control diet; L - 2I-day-old offspring of mothers fed diet enriched with lard; HVF - 2I-day-old offspring of mothers fed diet enriched with hydrogenated vegetable fat; FO 2I-day-old offspring of mothers fed diet enriched with fish oil. Groups were compared by ANOVA for repeated measure (body parameters) or one-way ANOVA (relative weight of RET), followed by a Bonferroni post hoc test. Data are mean \pm SEM of 20 determinations per group. ${ }^{a} p \leq 0.05$ versus SO. ${ }^{b} p \leq 0.05$ versus $L$. ${ }^{c} p \leq 0.05$ versus HVF.

Abbreviations: ANOVA, analysis of variance; FO, fish oil; HVF, hydrogenated vegetable fat; L, lard; RET, retroperitoneal white adipose tissue; SEM, standard error of the mean; SO, soybean oil.

Table 5 Serum concentrations of LPS, hepatic protein content of TNF- $\alpha$, IL-6 and IL-10, and IL-I0/TNF- $\alpha$ ratio in the liver of 2 I-dayold rat offspring

\begin{tabular}{lllll}
\hline Experimental parameters & SO & L & HVF & FO \\
\hline $\begin{array}{l}\text { Serum concentration } \\
\text { LPS }(E U / m L)\end{array}$ & $3.446 \pm 0.58 \mathrm{I}$ & $4.469 \pm 0.469$ & $3.772 \pm 0.616$ & $2.135 \pm 0.384^{\mathrm{a}}$ \\
Hepatic protein content & & & & \\
TNF- $\alpha(\mathrm{pg} / \mathrm{mg})$ & $40.287 \pm 3.669$ & $32.23 \mathrm{I} \pm 2.238$ & $28.570 \pm 2.901$ & $32.680 \pm 3.276$ \\
$\mathrm{IL}-6(\mathrm{pg} / \mathrm{mg})$ & $92.219 \pm 11.596$ & $71.256 \pm 5.784$ & $69.997 \pm 7.08 \mathrm{I}$ & $68.029 \pm 6.617$ \\
IL-10 (pg/mg) & $32.296 \pm 2.690$ & $28.556 \pm 2.130$ & $26.330 \pm 2.014$ & $27.216 \pm 1.804$ \\
IL- $10 / \mathrm{TNF}-\alpha$ ratio $(\mathrm{pg} / \mathrm{mg})$ & $0.826 \pm 0.055$ & $0.905 \pm 0.072$ & $0.960 \pm 0.067$ & $0.858 \pm 0.068$ \\
\hline
\end{tabular}

Notes: SO - 2I-day-old rat offspring of mothers fed control diet; L - 2I-day-old offspring of mothers fed diet enriched with lard; HVF - 2I-day-old offspring of mothers fed diet enriched with hydrogenated vegetable fat; FO - 2I-day-old offspring of mothers fed diet enriched with fish oil. Groups were compared by one-way ANOVA, followed by a Bonferroni post hoc test. Data are mean \pm SEM of $9-10$ determinations per group. ${ }^{a} \leq \leq 0.05$ versus $L$.

Abbreviations: ANOVA, analysis of variance; FO, fish oil; HVF, hydrogenated vegetable fat; L, interleukin; L, lard; LPS, lipopolysaccharides; SEM, standard error of the mean; SO, soybean oil; TNF- $\alpha$, tumor necrosis factor alpha.

FO ( $p=0.017)$ groups (Figure 3A). Gene expression of the ADIPOR2 gene decreased significantly in the FO group relative to the $\mathrm{SO}$ group $(p=0.005$; Figure $3 \mathrm{~B}$ ). In addition, the levels of TNFR1 and IL6R mRNA were similar among the groups of 21-day-old pups (Figure 3C and D, respectively).

\section{TNFR I, IL6R $\alpha$, IL I OR $\alpha$ and ADIPOR2 protein expression in the livers of 2 I-day-old rat offspring}

As shown in Figure 4C, the IL10R $\alpha$ protein levels in the liver were significantly higher in the HVF group than in the SO 

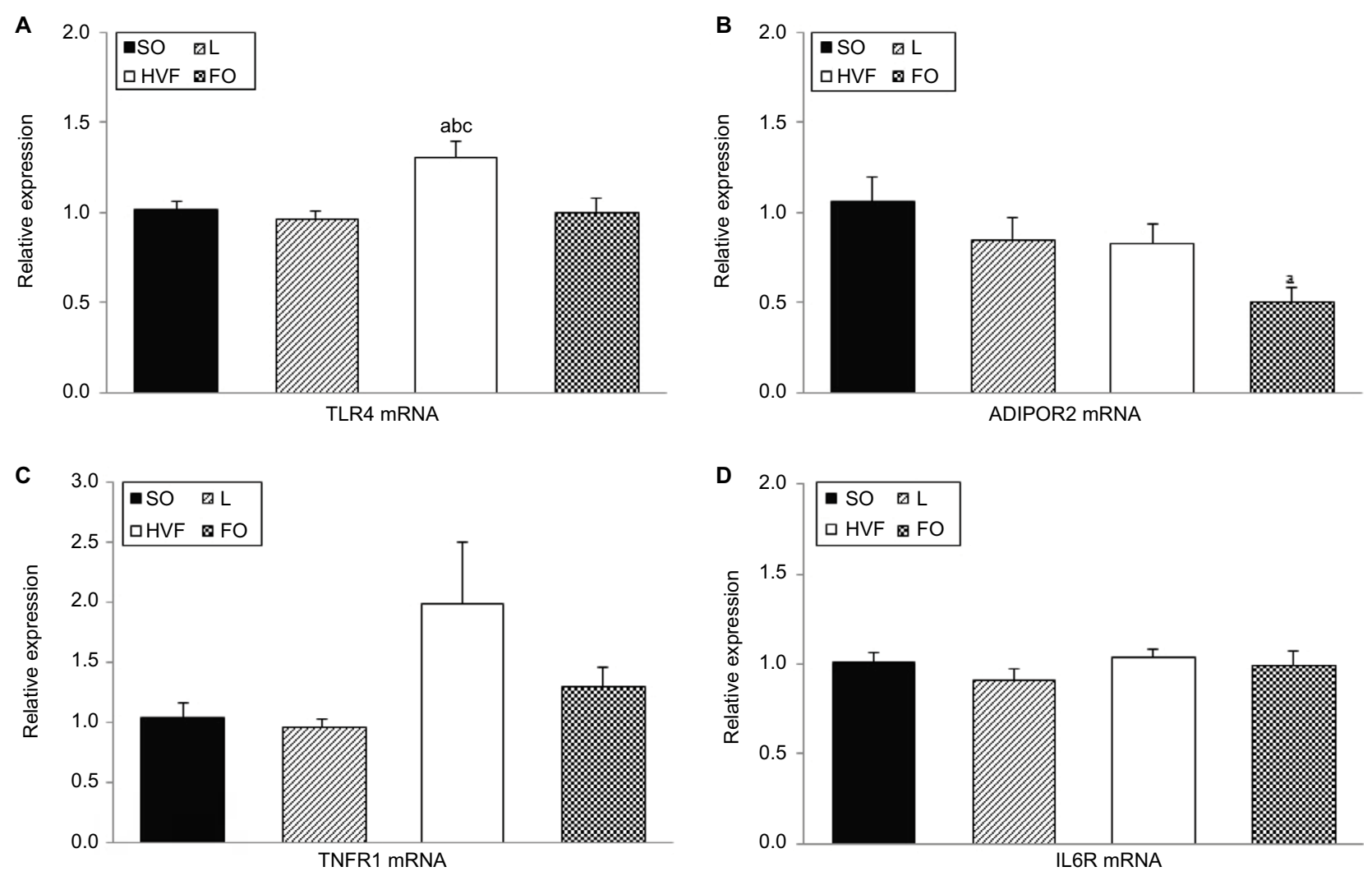

Figure 3 Effects of maternal intake of distinct sources of lipids during pregnancy and lactation on the gene expression of receptors involved in the inflammatory responses of the 21 -day-old rat offspring.

Notes: (A) Gene expression of TLR4 in the liver. (B) Gene expression of ADIPOR2 in the liver. (C) Gene expression of TNFRI in the liver. (D) Gene expression of IL6R in the liver. SO - 2I-day-old rat offspring of mothers fed control diet; L-2I-day-old offspring of mothers fed diet enriched with lard; HVF - 2I-day-old offspring of mothers fed diet enriched with hydrogenated vegetable fat; FO - 2I-day-old offspring of mothers fed diet enriched with fish oil. Groups were compared by one-way ANOVA, followed by a Bonferroni post hoc test. Data are mean \pm SEM of $8-10$ determinations per group. ${ }^{a} p \leq 0.05$ versus $S O$. ${ }^{b} p \leq 0.05$ versus $L$. ${ }^{c} p \leq 0.05$ versus FO.

Abbreviations: ADIPOR2, adiponectin receptor 2; ANOVA, analysis of variance; FO, fish oil; HVF, hydrogenated vegetable fat; IL6R, interleukin 6 receptor; L, lard; SEM, standard error of the mean; SO, soybean oil; TLR4, toll-like receptor 4; TNFRI, tumor necrosis factor receptor I.

group ( $p=0.026)$. However, we did not observe significant intergroup differences in the expression of TNFR1, IL6R $\alpha$ and ADIPOR2 proteins in the liver (Figure 4A, B and D, respectively).

\section{TLR4, myeloid differentiation factor 88 (MyD88), TNF receptor-associated factor 6 (TRAF6), p-IKK $\alpha+\beta$, p-NFKB p50 and $P-N F \kappa B$ p 65 protein expression in the livers of $2 \mathrm{I}$-day-old rat offspring}

As shown in Figure 5D, the protein expression of p-IKK $\alpha+\beta$ in the liver was higher in the HVF group than in the SO group $(p=0.027)$. Additionally, the protein levels of $\mathrm{p}-\mathrm{IKK} \alpha+\beta$ $(p=0.024)$ and $\mathrm{p}-\mathrm{NF \kappa B} \mathrm{p} 50(p=0.024)$ were lower in the FO group relative to the HVF group (Figure 5D and E, respectively). In contrast, the protein levels of TLR4, MyD88, TRAF6 and p-NFkB p65 in the liver did not differ among 21-day-old offspring in the SO, L, HVF and FO groups (Figure 5A, B, C and F, respectively).

\section{Discussion}

Few studies have discussed the importance of dietary quality and its potential effects on metabolic homeostasis, especially in the context of fetal programming. Therefore, this study was novel in its aim to investigate the influence of a normal-fat maternal diet, modified only by the source of lipids offered to dams without changing the total lipid content, during pregnancy and lactation on development and proinflammatory responses in the offspring.

The maternal corporal parameters and metabolic efficiency during the pregnancy and lactation periods were similar among our experimental groups. Changes in food intake were only observed during the first week of pregnancy in the M-HVF group; however, this difference did not remain over the experimental period. Therefore, our data do not suggest 

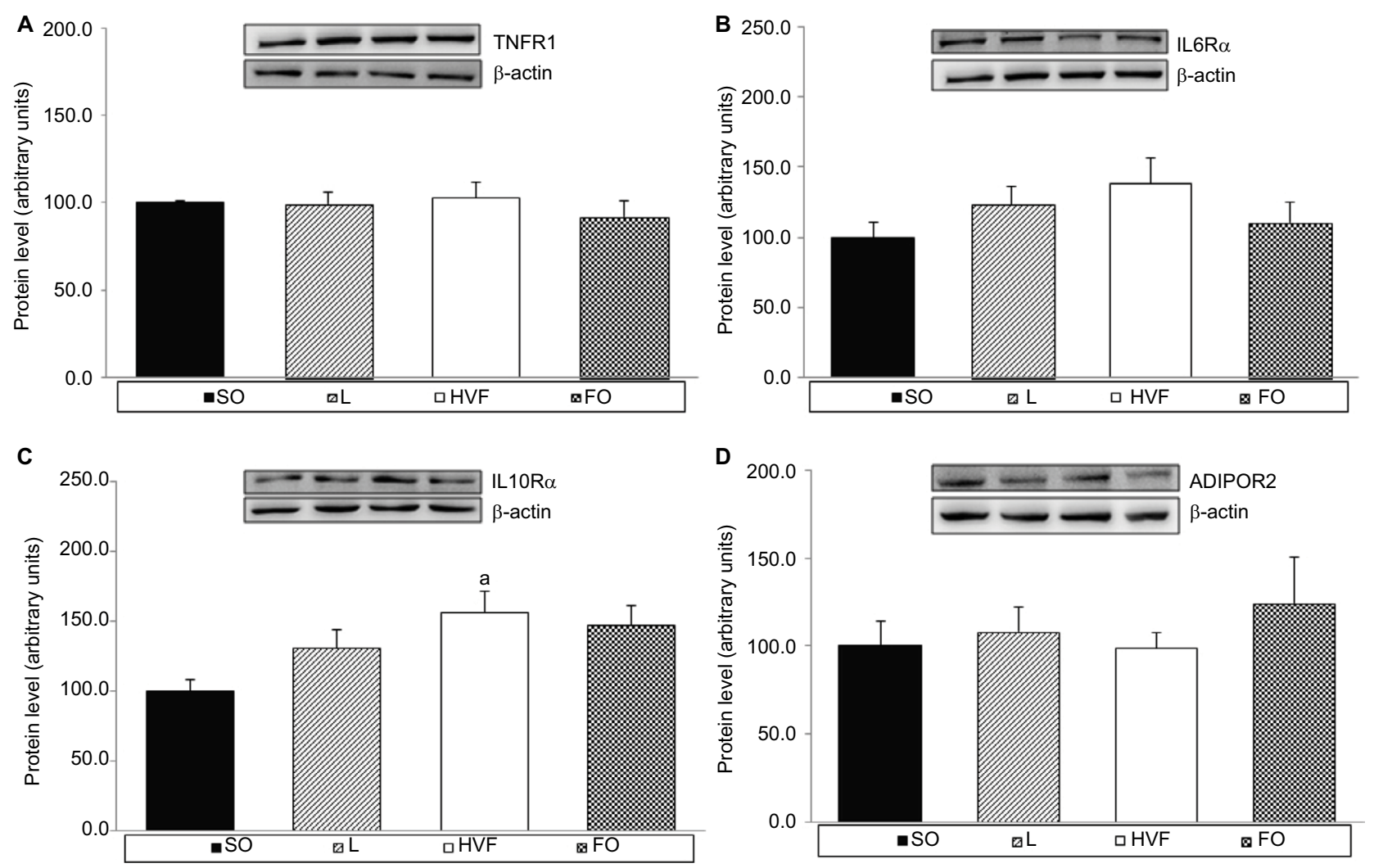

Figure 4 Effects of maternal intake of distinct sources of lipids during pregnancy and lactation on the protein expression of receptors involved in the inflammatory responses of the 21 -day-old rat offspring.

Notes: (A) Protein expression of TNFRI in the liver. (B) Protein expression of IL6R $\alpha$ in the liver. (C) Protein expression of ILIOR $\alpha$ in the liver. (D) Protein expression of ADIPOR2 in the liver. SO - 2I-day-old offspring of mothers fed control diet; L - 2I-day-old offspring of mothers fed diet enriched with lard; HVF - 2I-day-old offspring of mothers fed diet enriched with hydrogenated vegetable fat; FO - 2I-day-old offspring of mothers fed diet enriched with fish oil. Groups were compared by one-way ANOVA, followed by a Bonferroni post hoc test. Data are means \pm SEM of $9-10$ determinations per group. ${ }^{a} \leq 0.05$ versus $S O$.

Abbreviations: ADIPOR2, adiponectin receptor 2; ANOVA, analysis of variance; FO, fish oil; HVF, hydrogenated vegetable fat; IL6R, interleukin 6 receptor; TNFRI, tumor necrosis factor receptor I; SEM, standard error of the mean; SO, soybean oil.

associations between the maternal corporal results and the observations related to offspring development, body weight and adiposity in this study.

The maternal consumption of diets enriched with $\mathrm{L}$ and HVF during pregnancy and lactation increases the body weight, body weight gains and relative weight of RET of the pups. Notably, the HVF group exhibited a reduction in body weight at birth that was accompanied by increases in the body weight and body weight gain at 21 days of life, suggesting that this group experienced catch-up growth. In general, these results could be attributed to increases in visceral fat deposits in the L and HVF groups.

Some studies did not report significant differences in the corporal parameters of offspring exposed to maternal SFAbased diets during early life..$^{14,21,31-33}$ However, the authors demonstrated increases in body weight and/or adipose tissue deposits in the adult offspring of dams that received highfat (HF) diets enriched with lard during pregnancy and/or lactation..$^{11,14,18}$ Accordingly, it is difficult to interpret our results concerning the body parameters of offspring exposed to lard-based normal-fat diets during early life, as most of the available data in the field has reported the effects of SFAbased HF diets on offspring development.

Regarding the maternal consumption of TFA-rich diets, De Souza et $\mathrm{a}^{34}$ found that male offspring exposed to a normal-fat diet containing TFAs during pregnancy, lactation and after weaning (until 45 days of age) exhibited increases in body weight on postnatal days 7 and 14. In a prospective study, Cohen et a ${ }^{35}$ observed that a higher maternal consumption of TFAs during the second trimester of pregnancy was associated with greater fetal growth. Similarly, de Oliveira et $\mathrm{al}^{12}$ used the same experimental design as in this study and demonstrated an increase in the RET relative weights of 21-day-old pups belonging to the HVF group.

Herein, the early exposure of 21-day-old pups to FO in the maternal diet during pregnancy and lactation triggered decreases in body weight, body weight gain and relative RET tissue weights, without affecting body length. These results 

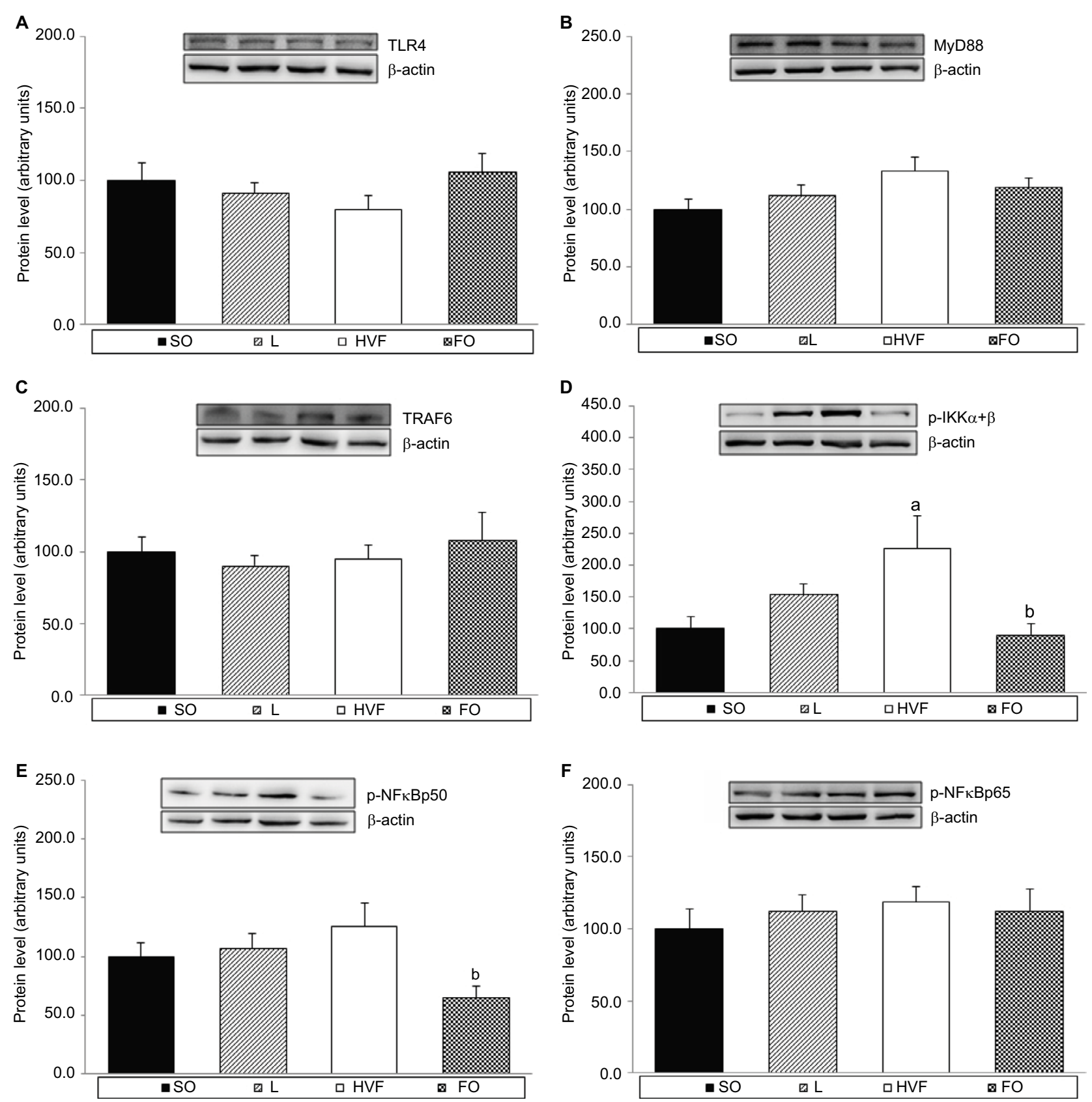

Figure 5 Effects of maternal intake of distinct sources of lipids during pregnancy and lactation on the production of key proteins in TLR4 signaling pathway of the 2 I-day-old rat offspring.

Notes: (A) Protein expression of TLR4 in the liver. (B) Protein expression of MyD88 in the liver. (C) Protein expression of TRAF6 in the liver. (D) Protein expression of IKK $\alpha+\beta$ phosphorylated form (p-IKK $\alpha+\beta)$ in the liver. (E) Protein expression of NFKB p50 (p-NFKB p50) phosphorylated form in the liver. (F) Protein expression of NFKB p65 (p-NFKB p65) phosphorylated form in the liver. SO - 2I-day-old offspring of mothers fed control diet; $L$ - 2I-day-old offspring of mothers fed diet enriched with lard; HVF - 2I-day-old offspring of mothers fed diet enriched with hydrogenated vegetable fat; FO - 2I-day-old offspring of mothers fed diet enriched with fish oil. Groups were compared by one-way ANOVA, followed by a Bonferroni post hoc test. Data are mean \pm SEM of $6-10$ determinations per group. ${ }^{a} p \leq 0.05$ versus SO. ${ }^{b} p \leq 0.05$ versus HVF. Abbreviations: ANOVA, analysis of variance; FO, fish oil; HVF, hydrogenated vegetable fat; L, lard; MyD88, myeloid differentiation factor 88 ; SEM, standard error of the mean; SO, soybean oil; TLR4, toll-like receptor 4; TRAF6, TNF receptor-associated factor 6.

indicate that the beneficial changes in offspring body composition in the FO group were not accompanied by impairments in the growth and development of the pups.

Similarly, Jimenez et $\mathrm{a}^{22}$ demonstrated that the maternal consumption of a diet containing fish oil, which is rich in
DHA and EPA, during pregnancy and lactation led to reduced offspring body weights from birth (day 0) until day 30. In contrast to our results, however, those authors reported that pups exposed to an FO-based maternal diet had shorter body lengths. ${ }^{22}$ Moreover, Siemelink et $\mathrm{al}^{20}$ reported that the male 
offspring of dams that were fed a fish oil-based diet prior to mating and during pregnancy and lactation had lower body weights from birth until postnatal day 21 . Any change in the corporal evolution of a pup can have deleterious effects on adequate growth and development throughout life. Therefore, our positive conclusion regarding the development of 21-dayold offspring exposed to FO during early life was based on the association between the weights and lengths of the animals at the end of the experimental period.

To investigate the proinflammatory status of 21-day-old pups, we analyzed the serum concentrations of LPS and the gene and protein expression levels of different receptors associated with pro- and anti-inflammatory responses and intracellular proteins involved in the TLR4 signaling pathway. TLR4 is a type I transmembrane protein associated with the innate immune system that is mostly expressed on hematopoietic (e.g., macrophages and dendritic cells) and non-hematopoietic cells (e.g., adipocytes and hepatocytes). TLR4 recognizes LPS derived from the outer membranes of gram-negative bacteria, which usually inhabit the host intestine. Several studies have reported that dietary patterns (e.g., HF diets) may alter the gut permeability and bacterial composition, leading to an increase in LPS levels in the bloodstream; thus, TLR4 has been identified as an important regulator of metabolic inflammation in many tissues. ${ }^{36,37}$

In summary, upon stimulation by LPS, TLR4 recruits downstream adaptor proteins such as MyD88, which activates TRAF6. Subsequently, the IKB kinase (IKK) complex, which comprises two kinases (IKK $\alpha$ and IKK $\beta$ ) and a regulatory subunit (NEMO/IKKr), is activated via phosphorylation. Lastly, NFKB is activated and it subsequently translocates to the nucleus to stimulate the production of proinflammatory cytokines, including TNF- $\alpha$ and IL- $6 .{ }^{38}$ In a review, Yu et $\mathrm{al}^{39}$ reported an association of the activation of NFKB family members (including p50 and p65 subunits) with the phosphorylation of serine residues.

In this work, we observed an increase in TLR4 mRNA level in the HVF group, although this did not coincide with differences in the expression of the corresponding protein. Furthermore, we observed an increase in $\mathrm{p}-\mathrm{IKK} \alpha+\beta$ protein expression in the livers of pups. Previous studies conducted by our research group observed the proinflammatory effects of maternal HVF intake during pregnancy and lactation in 21-day-old rat offspring. ${ }^{9,12,15,17}$ Using the same experimental model, de Oliveira et $\mathrm{al}^{12}$ reported an increase in TLR4 mRNA levels in the soleus muscle and in TRAF6 protein expression in the RET of pups. Similarly, other authors reported increases in IL6R mRNA levels and TNF- $\alpha$ protein levels in the RET, as well as decreases in the serum level of adiponectin (anti-inflammatory adipokine) and the gene and protein expression of adiponectin receptors (ADIPOR1 and/ or ADIPOR2) in the RET, liver, soleus muscle and/or extensor digitorum longus muscles of 21-day-old offspring. ${ }^{9,12,15,17}$

In agreement with our previous results, maternal HVF consumption during pregnancy and lactation also affected the anti-inflammatory status of the HVF group in this study, as demonstrated by increases in IL10R $\alpha$ protein levels in the liver. The anti-inflammatory cytokine IL-10 is produced by many cells of the innate and adaptive immune systems, including macrophages, monocytes, neutrophils, CD4+ T and $\mathrm{B}$ cells. In a review, Shouval et $\mathrm{al}^{40}$ reported that the recognition of pathogen-associated molecular patterns (e.g., LPS) by pattern recognition receptors (e.g., TLR4) could trigger IL-10 synthesis. In fact, Boonstra et $\mathrm{al}^{41}$ observed that IL-10 production by macrophages was induced upon stimulation with LPS via the MyD88-dependent TLR4 signaling pathway.

Additionally, the IL-10 receptor comprises two different subunits, IL10R $\alpha$ and IL10R $\beta$. All IL-10-responsive cells, including most hematopoietic cells, express IL10R $\alpha$ at a basal level; however, various types of cells upregulate IL $10 \mathrm{R} \alpha$ expression upon activation, which suggests the importance of this receptor in inhibitory pathways. ${ }^{40}$ Crepaldi et $\mathrm{al}^{42}$ demonstrated marked increases in IL10R $\alpha$ gene and protein expression in neutrophils cultured with LPS. Furthermore, the same authors suggested that LPS may influence the synthesis and release of proinflammatory mediators while triggering cellular alterations that would allow immediate responses to anti-inflammatory signals (e.g., IL-10), thereby limiting the magnitudes of inflammatory reactions. ${ }^{42}$ Therefore, one might speculate that the increased IL10R $\alpha$ levels in the livers of pups in the HVF group could be consequent to the increase in proinflammatory responses associated with the TLR4 signaling pathway.

Several studies reported that some SFAs, such as palmitate, could modulate the activation of the TLR4 signaling pathway in a manner similar to LPS and could thus induce the production of proinflammatory cytokines, which are associated with the onset of many chronic diseases and metabolic disorders such as CVD and insulin resistance..$^{36,37,43}$ However, we did not observe differences in the proinflammatory status of 21-day-old pups in the L group in this study. Therefore, the dietary lipid content and the long-term effects of a lardbased maternal diet during pregnancy and lactation on the offspring's development and inflammatory responses, mainly those mediated by TLR4, should be considered. 
In contrast to groups exposed to other maternal dietary lipid sources, the FO group exhibited reduced serum LPS concentrations and $\mathrm{p}-\mathrm{IKK} \alpha+\beta$ and $\mathrm{p}-\mathrm{NF} \kappa \mathrm{B}$ p50 subunit protein expression relative to $\mathrm{L}$ and HFV groups, respectively. These findings suggest that n-3 PUFAs might contribute to the proinflammatory status of the offspring. The antiinflammatory properties of n-3 PUFA, which are mediated via the suppression of TLR4, TLR4-related proteins and $\mathrm{NF} \kappa \mathrm{B}$ activation, have been well established. ${ }^{44-47}$ In fact, Oh et $\mathrm{al}^{46}$ observed that DHA inhibited the LPS-induced phosphorylation of IKK $\beta$ and the secretion of TNF- $\alpha$ and IL-6 in a cell culture experiment, ${ }^{46}$ thereby suggesting the importance of n-3 PUFA in blocking NFאB activation and preventing the TLR4 proinflammatory signaling cascade. Similarly, Liu et $\mathrm{al}^{47}$ reported that fish oil had a mitigating effect on the proinflammatory targets within the LPS-induced TLR4 signaling pathway.

Interestingly, in our study, we observed a decrease in the gene expression of ADIPOR2 in the livers of the FO group; however, the protein levels of this anti-inflammatory receptor did not differ among the experimental groups. Adiponectin, an adipokine released by the adipose tissue, has been shown to exert anti-inflammatory, antidiabetic, antiatherosclerotic and cardioprotective activities through binding to two distinct receptors, ADIPOR1, which is most abundantly expressed in the skeletal muscle, and ADIPOR2, which is expressed predominantly in the liver. ${ }^{48,49}$

Genetic information is transcribed from DNA to mRNA, which serves as a template for the translation and subsequent synthesis of proteins by ribosomes. ${ }^{50}$ Therefore, we hypothesize that in this early phase of life, the translation of ADIPOR2 mRNA may not have begun, and therefore, we observed no significant differences in the protein levels of ADIPOR2 in the pups. Additionally, protein expression might be positively regulated by epigenetic dynamic changes, such as the actions of noncoding RNAs (miRNAs), which may have mitigated the reduction in ADIPOR2 protein levels in 21-day-old rat offspring.

In conclusion, whereas early exposure to L (rich in SFAs) and HVF (rich in TFAs) had deleterious effects on somatic development, only HVF consumption during pregnancy and lactation impaired the proinflammatory status of the pups. In contrast, a maternal diet based on FO (rich in n-3 PUFA) improved adiposity in the 21-day-old offspring and appeared to be advantageous in terms of TLR4-mediated responses, particularly when compared to the L or HVF diets. However, further studies are needed to investigate the long-term effects of the maternal consumption of normal-fat diets based on different lipid sources during pregnancy and lactation on the adiposity, proinflammatory status and epigenetic patterns of the offspring.

\section{Acknowledgments}

The authors gratefully acknowledge CAPES (Coordinating Office for the Improvement of Higher Education) and FAPESP (grant \#2014/10683-0, São Paulo Research Foundation).

\section{Author contributions}

All authors contributed toward data analysis, drafting and revising the paper and agree to be accountable for all aspects of the work.

\section{Disclosure}

The authors report no conflicts of interest in this work.

\section{References}

1. Barker DJ. In utero programming of chronic disease. Clin Sci (Lond). 1998;95(2):115-128.

2. Godfrey KM. Maternal regulation of fetal development and health in adult life. Eur J Obstet Gynecol Reprod Biol. 1998;78(2):141-150.

3. Godfrey KM. The role of the placenta in fetal programming - a review. Placenta. 2002;23(Suppl A):S20-S27.

4. Morley R, Dwyer T. Fetal origins of adult disease? Clin Exp Pharmacol Physiol. 2001;28(11):962-966.

5. Herrera E. Implications of dietary fatty acids during pregnancy on placental, fetal and postnatal development-a review. Placenta. 2002;23(Suppl A):S9-S19.

6. Lauritzen L, Carlson SE. Maternal fatty acid status during pregnancy and lactation and relation to newborn and infant status. Matern Child Nutr. 2011;7(Suppl 2):41-58.

7. Elias SL, Innis SM. Infant plasma trans, n-6, and n-3 fatty acids and conjugated linoleic acids are related to maternal plasma fatty acids, length of gestation, and birth weight and length. Am J Clin Nutr. 2001;73(4):807-814.

8. Priego T, Sánchez J, García AP, Palou A, Picó C. Maternal dietary fat affects milk fatty acid profile and impacts on weight gain and thermogenic capacity of suckling rats. Lipids. 2013;48(5):481-495.

9. Pisani LP, Oyama LM, Bueno AA, et al. Hydrogenated fat intake during pregnancy and lactation modifies serum lipid profile and adipokine mRNA in 21-day-old rats. Nutrition. 2008;24(3):255-261.

10. Pisani LP, Oller do Nascimento CM, Bueno AA, et al. Hydrogenated fat diet intake during pregnancy and lactation modifies the PAI-1 gene expression in white adipose tissue of offspring in adult life. Lipids Health Dis. 2008;7:13.

11. Odaka Y, Nakano M, Tanaka T, et al. The influence of a high-fat dietary environment in the fetal period on postnatal metabolic and immune function. Obesity (Silver Spring). 2010;18(9):1688-1694.

12. de Oliveira JL, Oyama LM, Hachul ACL, et al. Hydrogenated fat intake during pregnancy and lactation caused increase in TRAF- 6 and reduced AdipoR 1 in white adipose tissue, but not in muscle of 21 days old offspring rats. Lipids Health Dis. 2011;10(1):22.

13. Pimentel GD, Lira FS, Rosa JC, et al. Intake of trans fatty acids during gestation and lactation leads to hypothalamic inflammation via TLR4/NFKBp65 signaling in adult offspring. $J$ Nutr Biochem. 2012;23(3):265-271. 
14. Volpato AM, Schultz A, Magalhães-Da-Costa E, Correia MLDG, Águila MB, Mandarim-De-Lacerda CA. Maternal high-fat diet programs for metabolic disturbances in offspring despite leptin sensitivity. Neuroendocrinology. 2012;96(4):272-284.

15. Hachul ACL, Mennitti LV, de Oliveira JL, et al. Oligofructose supplementation $(10 \%)$ during pregnancy and lactation does not change the inflammatory effect of concurrent trans fatty acid ingestion on 21-dayold offspring. Lipids Health Dis. 2013;12(1):59.

16. Mennitti LV, Oliveira JL, Morais CA, et al. Type of fatty acids in maternal diets during pregnancy and/or lactation and metabolic consequences of the offspring. J Nutr Biochem. 2015;26(2):99-111.

17. Mennitti LV, Oyama LM, de Oliveira JL, et al. Maternal supplementation with Oligofructose $(10 \%)$ during pregnancy and lactation leads to increased pro-inflammatory status of the 21-D-Old Offspring. PLoS One. 2015;10(7): $\mathrm{e} 0132038$.

18. Gray C, Vickers MH, Segovia SA, Zhang XD, Reynolds CM. A maternal high fat diet programs endothelial function and cardiovascular status in adult male offspring independent of body weight, which is reversed by maternal Conjugated Linoleic Acid (CLA) supplementation. PLoS One. 2015;10(2):e0115994.

19. Elahi MM, Cagampang FR, Mukhtar D, Anthony FW, Ohri SK, Hanson MA. Long-term maternal high-fat feeding from weaning through pregnancy and lactation predisposes offspring to hypertension, raised plasma lipids and fatty liver in mice. Br J Nutr. 2009;102(4):514-519.

20. Siemelink M, Verhoef A, Dormans J, Span P, Piersma A. Dietary fatty acid composition during pregnancy and lactation in the rat programs growth and glucose metabolism in the offspring. Diabetologia. 2002;45(10):1397-1403

21. Sardinha FLC, Fernandes FS, Tavares do Carmo MG, Herrera E. Sex-dependent nutritional programming: fish oil intake during early pregnancy in rats reduces age-dependent insulin resistance in male, but not female, offspring. Am J Physiol Regul Integr Comp Physiol. 2013;304(4):R313-R320.

22. Jimenez MJ, Bocos C, Panadero M, Herrera E. Fish oil diet in pregnancy and lactation reduces pup weight and modifies newborn hepatic metabolic adaptations in rats. Eur J Nutr. 2017;56(1):409-420.

23. Hoile SP, Irvine NA, Kelsall CJ, et al. Maternal fat intake in rats alters 20:4n-6 and 22:6n-3 status and the epigenetic regulation of Fads 2 in offspring liver. J Nutr Biochem. 2013;24(7):1213-1220.

24. Zobel EH, Hansen TW, Rossing P, von Scholten BJ. Global changes in food supply and the obesity epidemic. Curr Obes Rep. 2016;5(4): 449-455.

25. Remig V, Franklin B, Margolis S, Kostas G, Nece T, Street JC. Trans fats in America: a review of their use, consumption, health implications, and regulation. J Am Diet Assoc. 2010;110(4):585-592.

26. Das UN. Essential fatty acids and their metabolites could function as endogenous HMG-CoA reductase and ACE enzyme inhibitors, antiarrhythmic, anti-hypertensive, anti-atherosclerotic, anti-inflammatory, cytoprotective, and cardioprotective molecules. Lipids Health Dis. 2008;7:37.

27. Reeves PG, Nielsen F, Fahey GJ. AIN-93 Purified diets for laboratory rodents: final report of the American institute of nutrition Ad Hoc writing committee on the reformulation of the AIN-76A Rodent Diet. J Nutr. 1993;123(11):1939-1951.

28. Reeves PG. Components of the AIN-93 Diets as Improvements in the AIN-76A Diet. J Nutr. 1997;127(5 Suppl):838S-841S.

29. Livak KJ, Schmittgen TD. Analysis of relative gene expression data using real-time quantitative PCR and the 2(-Delta Delta C(T)) Method. Methods. 2001;25(4):402-408.

30. Grubbs F. Procedures for detecting outlying observations in samples. Technometrics. 1969;11(1):1-21.
31. Fernandes FS, Sardinha FL, Badia-Villanueva M, Carulla P, Herrera E, Tavares do Carmo MG. Dietary lipids during early pregnancy differently influence adipose tissue metabolism and fatty acid composition in pregnant rats with repercussions on pup's development. Prostaglandins Leukot Essent Fat Acids. 2012;86(4-5):167-174.

32. Hollander KS, Tempel Brami C, Konikoff FM, Fainaru M, LeikinFrenkel A. Dietary enrichment with alpha-linolenic acid during pregnancy attenuates insulin resistance in adult offspring in mice. Arch Physiol Biochem. 2014;120(3):99-111.

33. Bispo KP, de Oliveira Rodrigues L, da Silva Soares de Souza É, et al. Trans and interesterified fat and palm oil during the pregnancy and lactation period inhibit the central anorexigenic action of insulin in adult male rat offspring. $J$ Physiol Sci. 2015;65(1):131-138.

34. De Souza AS, Rocha MS, Tavares do Carmo M das G. Effects of a normolipidic diet containing trans fatty acids during perinatal period on the growth, hippocampus fatty acid profile, and memory of young rats according to sex. Nutrition. 2012;28(4):458-464.

35. Cohen JF, Rifas-shiman SL, Rimm EB, Oken E, Gillman MW. Maternal trans fatty acid intake and fetal growth. Am J Clin Nutr. 2011;94(5): 1241-1247.

36. Jin C, Flavell RA. Innate sensors of pathogen and stress: linking inflammation to obesity. J Allergy Clin Immunol. 2013;132(2):287-294.

37. Watanabe Y, Nagai Y, Takatsu K. Activation and regulation of the pattern recognition receptors in obesity-induced adipose tissue inflammation and insulin resistance. Nutrients. 2013;5(9):3757-3778.

38. Lu Y, Yeh W, Ohashi PS. LPS/TLR4 signal transduction pathway. Cytokine. 2008;42(2):145-151.

39. Yu Y, Wan Y, Huang C. The biological functions of NF-kappaB1 (p50) and its potential as an anti-cancer target. Curr Cancer Drug Targets. 2009;9(4):566-571.

40. Shouval DS, Ouahed J, Biswas A, et al. Interleukin 10 receptor signaling: master regulator of intestinal mucosal homeostasis in mice and humans. Adv Immunol. 2014;122:177-210.

41. Boonstra A, Rajsbaum R, Holman M, et al. Macrophages and myeloid dendritic cells, but not plasmacytoid dendritic cells, produce IL-10 in response to MyD88- and TRIF-dependent TLR signals, and TLRindependent signals. J Immunol. 2006;177(11):7551-7558.

42. Crepaldi L, Gasperini S, Lapinet JA, et al. Up-regulation of IL-10R1 expression is required to render human neutrophils fully responsive to IL-10. J Immunol. 2001;167:2312-2322.

43. Rocha DM, Caldas AP, Oliveira LL, Bressan J, Hermsdorff HH. Saturated fatty acids trigger TLR4-mediated inflammatory response. Atherosclerosis. 2016;244:211-215.

44. Kalupahana NS, Claycombe KJ, Moustaid-Moussa N. (n-3) Fatty acids alleviate adipose tissue inflammation and insulin resistance: mechanistic insights. Adv Nutr. 2011;2(4):304-316.

45. Velloso LA, Folli F, Saad MJ. TLR4 at the crossroads of nutrients, gut microbiota, and metabolic inflammation. Endocr Rev. 2015;36(3): $245-271$.

46. Oh DY, Talukdar S, Bae EJ, et al. GPR120 is an Omega-3 fatty acid receptor mediating potent anti-inflammatory and insulin sensitizing effects. Cell. 2010;142(5):687-698.

47. Liu YH, Li XY, Chen CY, Zhang HM, Kang JX. Omega-3 fatty acid intervention suppresses lipopolysaccharide-induced inflammation and weight loss in mice. Mar Drugs. 2015;13(2):1026-1036.

48. Villarreal-Molina MT, Antuna-Puente B. Adiponectin: anti-inflammatory and cardioprotective effects. Biochimie. 2012;94(10):2143-2149.

49. Scheid MP, Sweeney G. The role of adiponectin signaling in metabolic syndrome and cancer. Rev Endocr Metab Disord. 2014;15(2):157-167.

50. Sauert M, Temmel H, Moll I. Heterogeneity of the translational machinery: variations on a common theme. Biochimie. 2014;114:39-47. 


\section{Publish your work in this journal}

The Journal of Inflammation Research is an international, peer-reviewed open access journal that welcomes laboratory and clinical findings on the molecular basis, cell biology and pharmacology of inflammation including original research, reviews, symposium reports, hypothesis formation and commentaries on: acute/chronic inflammation; mediators of inflammation; cellular processes; molecular mechanisms; pharmacology and novel anti-inflammatory drugs; clinical conditions involving inflammation. The manuscript management system is completely online and includes a very quick and fair peer-review system. Visit http://www.dove press.com/testimonials.php to read real quotes from published authors.

Submit your manuscript here: https://www.dovepress.com/journal-of-inflammation-research-journal 